\title{
Relações Sociais e Território: estudo no Arranjo Produtivo Local (APL) da castanha-da-Amazônia
}

\author{
Social Affairs and Definition of Territory: study in Local \\ Productive Arrangement (APL) of Brazil-Nuts in Acre State
}

\section{Gelciomar Simão Justen}

Doutorando em Administração pelo Programa de Pós-Graduação em Administração (PPGADM) da Universidade Federal do Paraná (UFPR). Curitiba, PR. Brasil. E-mail: simao.justen1984@gmail.com

\section{Mariluce Paes-de-Souza}

Doutora em Ciências Socioambientais e Pós-Doutora em Administração. Professora dos Programas de Pós-Graduação Mestrado em Administração (PPGMAD). Professora associada da Universidade Federal de Rondônia (UNIR), Porto Velho,RO. Brasil.

E-mail:mariluce@unir.br

\section{Resumo}

Esta pesquisa objetiva evidenciar os fatores que definem um tipo de território, enquanto rede de relações sociais no contexto do APL da Castanha-da-Amazônia, a partir da compreensão dos relacionamentos e suas articulações para o fortalecimento da atividade produtiva em potencial. Trata-se de pesquisa qualitativa de caráter descritivo, com estudo de campo para aplicação de questionários e entrevistas. Os resultados demonstram que o APL da Castanha-da-Amazônia no Estado do Acre possui como principal característica, no que diz respeito aos relacionamentos, dois territórios distintos, definidos a partir das relações sociais dos agentes, sendo um pautado em ações coletivas $e$ outro em ações individuais. A pesquisa contribui com a Teoria de APLs com a identificação de fatores relacionados a noção de pertencimento dos agentes, que podem fortalecer ou enfraquecer as relações sociais, agregando descobertas à área de administração quanto a importância de considerar os relacionamentos entre agentes na interação interorganizacional.

Palavras-chave: APL. Castanha-da-Amazônia. Território. Acre.

\section{Abstract}

This research aims to highlight the factors that define a type of territory, as a network of social relations in the context of the APL Brazil-Nuts, from the understanding of relationships and their articulations for the strengthening of potential productive activity. It is a qualitative research of descriptive character, with field study for application of questionnaires and interviews. The results show that the APL of Brazil-Nuts in Acre has as main characteristic, with regard to the relationships, two distinct territories, defined based on the social relations of the agents, being based on collective actions and another on Individual actions. The research contributes to the theory of APLs with the identification of factors related to the notion of agents belonging, which can strengthen or weaken social relations, adding findings to the area of administration regarding the importance of considering the relationships between agents in the interorganizational interaction.

Keywords: APL. Brazil-nuts. Territory. Acre. 


\section{INTRODUÇÃo}

A Castanha-da-Amazônia é uma amêndoa oriunda da Castanheira (Berthollethia Excelsa), tendo suas propriedades nutricionais reconhecidas mundialmente por seu alto valor proteico, de fibras, conteúdo de selênio e demais componentes benéficos para a saúde humana (SANTOS, 2012).

A Castanheira é uma planta com ocorrência em todo o bioma amazônico, que no Brasil, tem incidência nos Estados de Rondônia, Acre, Amazonas, Pará, Roraima, Amapá e Tocantins, sendo explorada para comercialização de diversas formas, seja in natura ou industrializada. Os maiores produtores brasileiros de Castanha são Amazonas, Acre e Pará (SOUZA FILHO et al., 2014). A Castanha-da-Amazônia também é conhecida nacionalmente como Castanha-do-Pará e internacionalmente como Castanha-do-Brasil. Todavia, a Castanheira é encontrada também nas áreas amazônicas da Bolívia, Peru, Colômbia, Venezuela, Suriname, Guiana e Guiana Francesa (HOMMA e MENEZES, 2008). Diante disso, em 1992, durante a

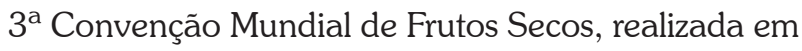
Manaus, foi convencionada sua nomenclatura como Castanha-da-Amazônia (EMBRAPA-RO, 2005).

A extração da Castanha constitui uma das principais fontes de trabalho e geração de renda de muitas comunidades da Amazônia, as quais se organizam para extrair o fruto. Existem também várias organizações, especialmente indústrias do ramo alimentício, que trabalham com o processamento e transformação da castanha agregando valor à amêndoa por meio de uma variedade de produtos, para comercialização a nível local, regional, nacional e até internacional. Algumas ainda, como as organizações do terceiro setor, privilegiam uma atuação característica ao contexto da região amazônica, chamando a atenção por seu histórico de ações, pois envolvem extrativistas, órgãos públicos, organizações não governamentais e outros parceiros, com fortes laços de cooperação em prol do desenvolvimento local.

A concentração de agentes com foco no fortalecimento de uma atividade produtiva remete à lógica de uma organização local com características específicas, especialmente no que diz respeito à articulação que emana das relações sociais para o alcance de objetivos comuns. Conforme atores sociais se inserem em deter- minado contexto de ações conjuntas, passam a compor uma organização pautada nas relações e articulações, congregando diversos agentes econômicos, políticos e sociais que, na busca por sinergias capazes de desenvolver e fortalecer uma atividade potencial forma um arranjo produtivo local (APL) (LASTRES et al., 1998).

Vilpoux e Oliveira (2010) ressaltam que os relacionamentos desenvolvidos no contexto de um arranjo, especialmente os informais, sofrem a influência do território enquanto rede de relações sociais que se projetam no tempo e no espaço (ALBAGLI, 2004). Todavia, para que seja possível definir o território de um APL, é necessário compreender, primeiramente, como se dão os relacionamentos no contexto desse arranjo, bem como evidenciar os fatores que exercem influência na formação da rede de relações sociais.

$\mathrm{Na}$ região amazônica, pode-se perceber a existência de APLs, uns em formação e outros já bem formatados, como é o caso da produção de Castanha-da-Amazônia no Estado do Acre, que conta com a participação de diversos agentes envolvidos na atividade econômica de extração, processamento e comercialização de produtos ou derivados. Sales (2009) menciona a existência de um arranjo institucional formado por laços de cooperação entre diversas instituições, circundando a Cooperativa Central de Comercialização Extrativista do Acre - COOPERACRE, a qual congrega extrativistas organizados em associações e cooperativas, parceiros externos e entidades governamentais, evidenciando que os agentes se inserem em um contexto de relações sociais, inclusive relações consolidadas e de longas datas.

Tal realidade remete à percepção de um APL, comparando-se à proposição de Lastres e Cassiolato (2003), em que um arranjo é composto por produtores, organizações internas, externas e outros que formam um conjunto de partes interagentes e interdependentes, inseridos em um espaço geográfico e que desenvolvem relações econômicas e não econômicas entre si, trocam conhecimentos e partilham de mecanismos de governança.

Nesta dinâmica, instiga-se a compreender a definição do território existente no APL da Castanha-da-Amazônia no Estado do Acre, uma vez que há indicativos de relações sociais consolidadas na região visando o fortalecimento de uma atividade produtiva em potencial, com foco no desenvolvimento local, o 
que remete a formular a seguinte questão norteadora da presente pesquisa: quais os fatores que definem o território no arranjo produtivo local (APL) da Castanha-da-Amazônia no Estado do Acre?

Assim, o objetivo geral desta pesquisa consiste em evidenciar os fatores que definem o território, enquanto rede de relações sociais, no contexto do APL da Castanha-da-Amazônia no Estado do Acre, a partir da compreensão dos relacionamentos desenvolvidos pelos agentes inseridos no arranjo e suas articulações para o fortalecimento da atividade produtiva em potencial.

\section{Referencial Teórico}

Nesta seção será discutido e apresentado o referencial teórico que embasou o presente trabalho.

\subsection{Contexto dos PFNM e a Castanha-da- Amazônia}

As florestas brasileiras, especialmente na região amazônica, são detentoras de recursos possíveis de aproveitamento pelas populações locais, fornecendo-lhes fontes primárias de subsistência e renda.

Neste sentido, apresentam-se os Produtos Florestais Não Madeireiros (PFNM), como alternativa viável para o modo de vida sustentável nas regiões de florestas, sendo todos os produtos provenientes da floresta e que não sejam madeira, como frutos, folhas, flores, raízes, resinas, látex, cipós, palmitos, ervas e outros que se enquadram neste perfil (MACHADO, 2005).

Nos últimos tempos os PFNM estão aparecendo de maneira mais significativa no mercado, em forma de produtos para consumo e que, com sua comercialização, geram renda para as comunidades locais que vivem de atividades extrativas. Cabe ressaltar que o aproveitamento equilibrado do PFNM tem se destacado dentre as alternativas de conservação da biodiversidade, uma vez que gerando renda será prezado por sua perenidade, de maneira a se evitar seu esgotamento (BENTES-GAMA, 2005). Essa visão é corroborada por Pedrozo et al. (2011, p. 89) que analisam as atividades com PFNM sob a ótica da sustentabilidade, afirmando que "[...] a preservação da floresta $e$ a boa utilização pode ser uma fonte de obtenção de bens florestais não madeireiros e serviços ambientais socialmente $e$ economicamente rentáveis".
Nesse contexto, um importante PFNM é a Castanha-da-Amazônia, amêndoa oriunda da Castanheira, árvore de grande porte que se apresenta somente na Amazônia, desde o Brasil até os demais países da América do Sul que se inserem neste bioma.

Para os povos da Amazônia, além da importância social e cultural, como os índios Zoró que praticam rituais com o fruto, a Castanha tem destacada a sua importância econômica para a economia local (SALOMÃO, 2014). Com a decadência da borracha, a Castanha passou a constituir o principal produto extrativista na exportação, tendo produção média anual em torno de 30 mil toneladas. O Brasil é o segundo maior exportador de Castanha, perdendo somente para a Bolívia (APIZ, 2008). Mais de 90\% da Castanha brasileira é exportada para países como Estados Unidos, Inglaterra, Alemanha, França e Itália, sendo estes os maiores compradores. Todavia, apesar da sua importância para o mercado internacional, vale ressaltar que a dinâmica produtiva em torno da Castanha, envolvendo desde o extrator até o consumidor final, é uma importante fonte de renda para milhares de pessoas que vivem na Amazônia, como extrativistas, povos indígenas, agricultores, dentre outros (APIZ, 2008; SOUZA FILHO; PEDROZO; PAES-DE-SOUZA, 2011).

Desde os tempos mais antigos, a Castanheira sempre foi explorada para diversos fins, seja para coleta do fruto ou para extração de madeira. A árvore também foi muito derrubada a partir de algumas políticas de colonização, em que as matas foram transformadas em pastagens ou em áreas de cultivo agrícola, fatores estes que levaram a Castanheira a entrar na lista de espécies em extinção (HURTIENE, 2005; SALOMÃO, 2014).

A APIZ (2008) contextualiza que a conservação da Castanha depende de medidas que contenham a exploração ilegal da madeira e à expansão dos desmatamentos. Uma alternativa para tal é o fortalecimento das associações comunitárias e o desenvolvimento de projetos e programas que contribuem para aumentar a renda das famílias a partir das florestas e castanhais em pé.

\subsection{Arranjo Produtivo Local (APL)}

As estruturas produtivas geram trabalho $e$ renda para os diversos atores nelas inseridos, bem como possibilitam a competição no mercado local, regional, nacional ou até mesmo internacional. Essas estruturas 
possuem formas diversificadas, variando de acordo com a região em que se localizam. Possuem também diferentes nomenclaturas, dentre elas os aglomerados de empreendimentos de um determinado setor econômico, também denominados de Clusters, redes, Distritos Industriais e, no contexto brasileiro, uma adaptação denominada de arranjos produtivos locais (APLs) (TAHIM, 2008).

Os distritos industriais foram observados no século XIX, concentrados na periferia dos grandes centros produtores ingleses. Estes distritos eram caracterizados por formas específicas de cooperação entre seus agentes, resultando na redução dos custos de produção, o que por sua vez permitia às pequenas organizações competirem no mercado com as grandes industriais têxteis da época (MARSHALL, 1920).

Mais recentemente, outro fenômeno neste sentido foi o surgimento da "Terceira Itália" no período entre as décadas de 1960 e 1970. De um lado localizava-se o sul italiano, extremamente pobre e sem perspectivas de desenvolvimento; do outro, estava o noroeste italiano, rico, mas em crise. Nesse meio termo percebe-se um fenômeno diferente na região nordeste, caracterizado por crescimento acelerado e grande geração de emprego. Isso chamou a atenção de pesquisadores sociais que resolveram pesquisar os fatos, encontrando assim uma forma de organização muito específica, congregando diversas empresas. Pôde-se perceber um aglomerado ou clusters de empresas produtoras de roupas, calçados, bolsas e processamento de alimentos, cooperando entre si e com outras organizações fornecedoras de insumos e equipamentos. Todas as empresas envolvidas nestas relações apresentavam índices de crescimento e desenvolvimento, bem como de competitividade (HUMPRHEY; SCHMITZ, 1995).

Um cluster é definido como uma concentração setorial e geográfica de empresas, que proporcionam o surgimento de fornecedores de matéria-prima e componentes, trabalhadores com habilidades específicas para um setor e serviços técnicos especializados. $\mathrm{O}$ cluster é caracterizado pela formação de uma rede de cooperação entre empresas, para o aprendizado mútuo e inovação coletiva (HUMPHREY; SCHMITZ, 1995).

Todavia, a abordagem de cluster, na sua concepção de organizações interagindo de forma sinérgica como nos aglomerados norte-americanos ou europeus, não se aplica a todas as realidades, pois existe uma diversidade de formas de organização. Assim, surge um novo conceito, que é o de arranjo produtivo local (APL), aplicável a diversos contextos.

As discussões no que diz respeito aos APL iniciaram-se no Brasil na década de 1990, a partir de uma estratégia do Governo Federal para fomentar o desenvolvimento local. Desde então a temática dos Arranjos Produtivos Locais tem ganhado espaço nos debates políticos e acadêmicos como uma forma de organização com características específicas e que merece consideração por sua abrangência (LASTRES et al., 1998).

Arranjo produtivo local é uma nomenclatura brasileira, similar ao conceito de "cluster", atribuída para aglomerações de empresas produtivas, de um mesmo setor econômico e que compartilham um território e um ambiente institucional comum. Os APLs constituem uma nova perspectiva na promoção do desenvolvimento econômico de uma região, congregando diversos atores, entre eles membros da sociedade civil, entidades educacionais e entidades públicas, sendo gerido de forma descentralizada, de acordo com as especificidades das organizações e da região em que se insere (CALHEIROS, 2010). Assim, entende-se por APL as aglomerações territoriais de agentes econômicos, políticos e sociais, com foco em um conjunto específico de atividades econômicas e que apresentam vínculos de interdependência.

Lastres et al. (1998) conceituam APL para a formulação de políticas públicas e de acordo com algumas variáveis para reconhecimento da existência dessas formas de organização. São elas:

a) Concentração setorial de empreendimentos no território: existência de um complexo produtivo que seja relevante para a economia local ou regional.

b) Concentração de indivíduos ocupados em atividades produtivas relacionadas com o setor de referência do APL: quantidade de indivíduos ocupados que seja relevante para a economia local ou regional, considerando as particularidades do setor e da região.

c) Cooperação entre os atores participantes do arranjo (empreendedores e demais participantes) em busca de maior competitividade: interação entre os atores com vistas ao desenvolvimento do arranjo. 
d) Existência de mecanismos de governança: canais capazes de liderar e organizar atores em prol dos objetivos, coordenarem ações, negociar processos decisórios e promover processos de geração e disseminação de conhecimentos.

O APL consiste em um aglomerado de organizações com foco na integração de agentes que competem no seu mercado cooperando entre si, a partir de experiências coletivas, parcerias, capital social $e$ governança, criando uma estrutura de relações capazes de promover o desenvolvimento local, uma vez que considera as dimensões espaciais, econômicas, ambientais, sociais, políticas e culturais. Nesta forma de organização, destacam-se as relações, como confiança, cooperação, aprendizado, reciprocidade, normas e valores vivenciados e partilhados. Todos esses fatores são empenhados em estratégias que possam proporcionar ganhos comuns aos envolvidos com o contexto coletivo da organização (PATIAS et al., 2015).

Os APLs congregam agentes preocupados com a transformação de determinada realidade, a partir do desenvolvimento de uma atividade específica capaz de fomentar outras atividades relacionadas, criando uma conexão entre atores locais e ações coordenadas com parceiros em busca de benefícios. Para tal, os APLs fomentam as capacidades empreendedoras dos seus agentes, dedicando também atenção especial às territorialidades no contexto das relações sociais, bem como para com o ambiente e a economia (ALVARENGA et al., 2013).

Nesse sentido, Alvarenga et al. (2013) realizaram pesquisa em um APL moveleiro no Ceará, tendo como objetivo analisar a ocorrência de práticas de desenvolvimento sustentável a partir da atividade do arranjo.

O APL em estudo comporta uma série de iniciativas que abarcam o desenvolvimento de capacidades empreendedoras para os empresários, melhor direcionamento dos investimentos, melhor utilização de matéria prima e recursos, competitividade dos produtos no mercado, cooperação entre firmas e parcerias institucionais.

O estudo apontou que essa dinâmica já apresenta resultados. No contexto econômico, percebe-se que o cenário local já está diferente, uma vez que o APL gera emprego e renda para a população, de maneira que proporcione também o crescimento do PIB. Na questão ambiental, o APL faz o plantio de árvores que servem de matéria-prima, bem como adora técnicas de produção mais limpa no que diz respeito à diminuição de resíduos descartados no ambiente. Todavia, o APL apresenta lacunas no aspecto social, pois na comunidade que se insere o arranjo ainda existe baixos graus de escolaridade, falta de infraestrutura educacional e deficiência nos serviços de saúde. Segundo os autores da pesquisa, as fábricas desenvolvem práticas de responsabilidade social com seus colaboradores, mas que não alcançam a comunidade como um todo. Identificou-se que este fator se dá devido a ausência de políticas, especificamente pela indiferença do poder municipal.

Os autores concluem sua pesquisa ressaltando que existem possibilidades de o APL ser sustentável contemplando todos os aspectos, uma vez que os agentes inseridos são integrados por relações sinérgicas que os permitem identificar as demandas locais com facilidade, bem como possuem capacidade para sensibilizar e atrair parceiros, inclusive públicos, convergindo esforços em ações que possam promover o desenvolvimento local com sustentabilidade.

Esses exemplos seguem o preconizado por Vilpoux e Oliveira (2010), que abordam os APL como organizações que emergem das articulações entre agentes, com interesses no desenvolvimento local, o que por sua vez carece de mecanismos de coordenação, orientação e controle das ações desenvolvidas pelos atores que se inserem neste contexto.

\subsection{Território}

No atual contexto econômico, diante de diversas realidades vivenciadas por indivíduos e grupos, chama atenção a maneira pela qual estes se articulam para o comum objetivo de mudar o contexto em que se inserem. A compreensão do território formado por esses atores, o qual transcende a abordagem material, criando uma esfera de laços culturais que se mantem fortalecidos, bem como cria uma identidade social que se projeta tanto no tempo quanto no espaço (BARRETO; MONASTIRSKY, 2010).

Lisboa (2007), conforme apresentado no Quadro 1 , faz uma diferenciação entre espaço, lugar, região $e$ território, comumente confundidos por falta de esclarecimentos acerca de cada um. 


\begin{tabular}{|c|l|}
\hline Conceito & \multicolumn{1}{c|}{ Definıção } \\
\hline \multirow{2}{*}{ Espaço } & $\begin{array}{l}\text { Refere-se a uma porção da superfície da } \\
\text { terra que se identifica pela natureza ou } \\
\text { pelo modo com que o homem interage } \\
\text { com o meio em que vive, retirando dali } \\
\text { o necessário para sua sobrevivência e } \\
\text { alterando suas características materiais. }\end{array}$ \\
\hline Lugar & $\begin{array}{l}\text { Refere-se a uma escala que pode ser } \\
\text { local ou regional, estando associada aos } \\
\text { indivíduos e grupos. O lugar é entendido } \\
\text { como uma parte do espaço em que o } \\
\text { homem desenvolve suas atividades sejam } \\
\text { elas de simples relações com os demais, ou } \\
\text { ligadas diretamente a sua sobrevivência. }\end{array}$ \\
\hline Região & $\begin{array}{l}\text { São porções do espaço que apresentam } \\
\text { características semelhantes. }\end{array}$ \\
\hline Território & $\begin{array}{l}\text { Diz respeito às relações de poder a que se } \\
\text { condicionam os agentes, definindo-se sob } \\
\text { forte influência de fatores socioculturais } \\
\text { presentes no lugar, na região ou no espaço. }\end{array}$ \\
\hline
\end{tabular}

Quadro 1: Definições importantes para a abordagem de território

Fonte: Adaptado de Lisboa (2007)

A abordagem de território parte do pressuposto de que o Estado não é mais o detentor da regulação social, econômica e política. Os atores sociais inseridos em determinado território, interagem e concebem organizações que passam a gerir os aspectos da região, por meio das instituições que se formam. Aqui, território não é concebido somente como um espaço de recursos definido, mas também como o modo de estabelecimento de grupos em determinado ambiente, com atividades que propiciem as relações entre os atores a partir da comunicação e aprendizado coletivo (FUINI, 2012).

Albagli (2004) contextualiza o território como um espaço apropriado por um ator, sendo definido e delimitado pelas relações de poder nos diferentes aspectos, como social, econômico, político, econômico e cultural. Na visão da autora, o território não se reduz a sua dimensão material ou concreta, sendo especialmente "[...] um campo de forças e uma teia ou rede de relações sociais que se projetam no espaço" (ALBAGLI, 2004, p. 26). Nesse sentido, a abordagem de território pode ser analisada por diferentes óticas, de acordo com o interesse e a abrangência de cada uma das seguintes dimensões:

a) Dimensão física: suas características geoecológicas e recursos naturais (clima, solo, relevo, vegetação), bem como aquelas resultantes dos usos e práticas dos atores sociais.

b) Dimensão econômica: formas de organização espacial dos processos sociais de produção (o que, como e quem nele produz), de consumo e de comercialização.

c) Dimensão simbólica: conjunto específico de relações culturais e afetivas entre um grupo e lugares particulares, uma apropriação simbólica de uma porção do espaço por um determinado grupo, um elemento constitutivo de sua identidade.

d) Dimensão sociopolítica: meio para interações sociais e relações de dominação e poder (quem e como o domina ou influencia).

Por muito tempo a noção de território permaneceu fechada dentro da abordagem espacial, atrelada à lógica do mercado em que se desenvolviam as relações comerciais do capitalismo. Porém, sempre existiu a necessidade de se aprofundar nas relações sociais $e$ políticas que podiam alterar o curso da busca pela riqueza. Assim, o território começa a ser considerado como um composto de relações e experiências sociais e políticas, que marcavam e caracterizavam determinado espaço geográfico. A partir dos anos de 1970, seguindo a lógica de Marx sobre a produção e reprodução social do espaço e do ambiente, é que a noção de território passa a ser abordada como uma forma de produção social, resultante dos conflitos e lutas de classes acerca do ambiente socialmente construído (BRANDÃO, 2007).

Os conceitos de território e espaço, mesmo diferentes, são diretamente ligados, podendo corresponder à mesma noção, dependendo da ótica que aborda. Todo território é um espaço, que pode ser geográfico, social ou cultural. O espaço se transforma em território a partir das relações sociais desenvolvidas pelos agentes que o compõe, podendo ser contraditórias, conflitivas ou solidárias. Tais relações podem construir um território sobre o espaço, bem como destruí-lo, fazendo com que o espaço volte a ser somente uma porção geográfica ocupada por indivíduos sem vínculos sociais. Por essa abordagem é que também se justifica o fato de que nem sempre o espaço é um território, pois isso depende das relações sociais que se desenvolvem em seu contexto (FERNANDES, 2005).

Haesbaert e Limonad (2007) alegam que o território não deve ser confundido ou reduzido à materialidade do espaço social construído no espaço 
geográfico. O território diz respeito à apropriação e domínio econômico e político de um espaço socialmente definido e partilhado por diversos atores ou grupos. Fernandes (2005) complementa essa abordagem trazendo a ideia de que o território pode ser tanto concreto quanto imaterial. Um território pode ser um país, um estado, uma região, uma vila, uma propriedade, o corpo, a mente, pensamento e conhecimento. $\mathrm{O}$ espaço geográfico ocupado por uma nação forma um território material, concreto, enquanto que os paradigmas, valores e outros fatores partilhados pela população que se insere nessa nação, formam o território imaterial. A diferença entre território e espaço consiste fundamentalmente na justificativa de que o espaço é perene, independente das relações entre os agentes que o ocupam, enquanto o território é intermitente, necessitando das relações sociais para ser construído, fortalecido e multiplicado ou destruído no espaço em que se insere (FERNANDES, 2005).

Para se compreender a noção de território deve-se partir de um pressuposto que evidencie sua distinção, construção e dimensões, como proposto por Haesbaert e Limonad (2007, p. 42, 43), conforme apresentado no Quadro 2.

\begin{tabular}{|c|c|}
\hline Evidenciação & \multicolumn{1}{c|}{ Definição } \\
\hline \multirow{2}{*}{ Distinção } & $\begin{array}{l}\text { "É necessário distinguir território e espaço } \\
\text { (geográfico); eles não são sinônimos, } \\
\text { apesar de muitos autores utilizarem } \\
\text { indiscriminadamente os dois termos - o } \\
\text { segundo é mais amplo que o primeiro". }\end{array}$ \\
& $\begin{array}{l}\text { "O território é uma construção histórica } \\
\text { e, portanto, social, a partir das relações } \\
\text { de poder (concreto e simbólico), que } \\
\text { envolve, concomitantemente sociedade }\end{array}$ \\
& $\begin{array}{l}\text { e espaço geográfico (que também é } \\
\text { sempre, de alguma forma, natureza)". }\end{array}$ \\
& $\begin{array}{l}\text { O território possui tanto uma dimensão mais } \\
\text { subjetiva, que se propõe denominar, aqui, } \\
\text { de consciência, apropriação ou mesmo, } \\
\text { em alguns casos, identidade territorial, e } \\
\text { uma dimensão mais objetiva, que se pode } \\
\text { denominar de dominação do espaço, } \\
\text { num sentido mais concreto, realizada por } \\
\text { instrumentos de ação político-econômica". }\end{array}$ \\
\hline Dimensãon
\end{tabular}

Quadro 2: Pressuposto para compreensão do território Fonte: Adaptado de Haesbaert e Limonad (2007)

O território é compreendido nas relações culturais e de trocas de experiências entre indivíduos e grupos, bem como pela forma que estas são expressas em determinado tempo e espaço. Quando indivíduos e grupos se relacionam, surgem mecanismos de trocas de influências culturais e hierarquias, criando assim um território que passa a ser vivido por determinada sociedade (BARRETO; MONASTIRSKY, 2010).

Para se construir um território é necessário que haja um lugar no espaço e condições favoráveis às relações que o definirão. Assim, os atributos essenciais para um território consistem em atores, interações, poderes, capacidades e iniciativas, ou seja, o território é condicionado ao poder que ele incorpora as inter-relações $e$ os atores que o formam, as iniciativas que ele gera $e$ as transformações a que ele obriga (REIS, 2002).

$\mathrm{Na}$ abordagem de território, faz-se necessário entender a territorialidade que Little (2002, p. 3) define como "[...] o esforço coletivo de um grupo social para ocupar, usar, controlar e se identificar com uma parcela específica de seu ambiente biofísico, convertendo-a assim em seu território". O território é entendido como resultante de fenômenos históricos, sociais e políticos vivenciados por determinado grupo social acerca da sua territorialidade. Portanto, para compreender um território, é necessário conhecer o seu processo de construção e afirmação, no contexto histórico dos indivíduos que o definiram (LITTLE, 2002).

O homem nasce com o território e o território nasce com a civilização, pois a partir do momento que o homem reconhece conscientemente o espaço em que está inserido, se apropria desse espaço, atribuindo valor e transformando-o para sua própria sobrevivência. Assim, o homem constrói o território ao se relacionar com outros da sua espécie, bem como é construído pelo território ao ficar condicionado às regras e padrões predominantemente característicos (HAESBAERT; LIMONAD, 2007).

Abordando o contexto do território, Justen et al. (2015) identificaram a existência de uma forte rede de relações sociais ao analisarem a estrutura de governança do Projeto Reca, organização coletiva de produtores rurais e extrativistas do Estado de Rondônia.

Os autores constaram que, na localidade, ocorre a presença de articulação entre diversos agentes, como produtores, associação e cooperativa do projeto, bem como parceiros institucionais que apoiam as ações. Os agentes presentes neste arranjo se envolvem em diversas formas de relações sociais, inclusive de longas datas e por meio de objetivos comuns, pautadas na cultura local, nos valores convencionados 
$e$, principalmente, na confiança entre os agentes. A pesquisa apontou que, com essa dinâmica, o Projeto Reca possui relações fortes, especialmente no que diz respeito à inclusão dos produtores e sua participação nas decisões e ações. Assim, os autores indicam que a organização conta com capital social desenvolvido e ativo nas atividades desenvolvidas, uma vez que são capacitados e preparados para atuarem como agentes de mudança no contexto local.

Os autores concluem relatando que essa forma de coordenação presente no local, insere a organização em um território de fortes relações sociais, de caráter duradouro, resultante em cooperação e ganhos coletivos, como presença no mercado, premiações e reconhecimentos por práticas sustentáveis.

Em resumo, o território nada mais é do que o espaço apropriado por formas de relações sociais que se evidenciam por meio das relações de poder entre agentes econômicos, políticos e sociais. Por possuir limites e fronteiras que dimensionam relações, laços culturais, sociais e econômicos, o território pode ser tanto uma convenção, algo partilhado pelos agentes, como uma confrontação, resultante dos conflitos e não aceitações dos mecanismos que regem as relações (FERNANDES, 2005). O autor utiliza as concepções de território para fazer uma breve relação com os movimentos sociais, em que os envolvidos são sujeitos ligados a um contexto social, que passam a lutar em conjunto para manter seu território, ou seja, sua identidade sociocultural. $\mathrm{O}$ autor finaliza sua abordagem discorrendo sobre o território como um mecanismo que protege os indivíduos das desigualdades econômicas e sociais em um contexto de exclusão ou marginalização pela sociedade.

Então, os territórios são formados no espaço geográfico por meio das relações sociais e políticas que se desenvolvem como dimensões de poder e controles sociais aceitos e partilhados por indivíduos e grupos que se constituem em agentes de mudanças.

\section{Procedimentos Metodológicos}

Realizou-se pesquisa de caráter qualitativa, com dados coletados e analisados com profundidade envolvendo toda a dinâmica do APL (CRESWELL, 2006). Quanto ao seu objetivo, a pesquisa se classifica como descritiva e explicativa, para compreender a realidade da produção de Castanha no Estado do Acre, sendo possível descrever os atores e agente envolvidos, suas articulações e as relações sociais que se projetam no contexto de um arranjo formatado (ANDER-EGG, 1978). A pesquisa também compreendeu um estudo de caso de um APL, amparado por pesquisa de campo para coleta de dados in loco (KERLINGER, 1979).

A pesquisa de campo consistiu em duas etapas, a primeira em novembro de 2014, na Associação Porongaba, para coleta de dados preliminares sobre a produção extrativista de Castanha-da-Amazônia no Estado Acre. Dessa fase participaram oito extrativistas, sendo o presidente da associação e sete associados. A outra etapa da pesquisa ocorreu no mês de fevereiro de 2015, que permitiram mapear o APL e identificar os agentes, os relacionamentos e as articulações para o fortalecimento da atividade produtiva principal do arranjo. Nesta fase da pesquisa participaram nove instituições, sendo: Associação dos Seringueiros do Cazumbá-Iracema e Cooperativa Agroextrativista dos Produtores Rurais do Vale do Rio Iaco (COOPERIA$\mathrm{CO})$ como agentes de representação dos extrativistas e produtores de Castanha; Casa do Seringueiro, no segmento de indústria de beneficiamento de Castanha; Secretaria de Extensão Agroflorestal e Produção Familiar (SEAPROF), Secretaria de Estado de Desenvolvimento Florestal, da Indústria, do Comércio e dos Serviços Sustentáveis (SEDENS), Serviço Brasileiro de Apoio a Micro e Pequenas Empresas (SEBRAE), Companhia Nacional de Abastecimento (CONAB), Instituto Nacional de Colonização e Reforma Agrária (INCRA) e Instituto Chico Mendes de Conservação da Biodiversidade (ICMBio) como instituições parceiras e articuladoras para ações no arranjo. Foram também entrevistados nove extrativistas da Associação dos Seringueiros do Cazumbá-Iracema.

Dessa maneira, no total, a pesquisa contou com a participação de 28 sujeitos, a partir de entrevistas com roteiros semiestruturados, formulários e questionários. Não foi possível estender a pesquisa para os demais municípios do APL devido às condições locais, marcadas por chuvas e enchentes, o que impossibilitou o acesso às cidades e, especialmente, às comunidades que trabalham com a Castanha-da-Amazônia.

Os dados da pesquisa, especialmente os que dizem respeito ao objetivo principal, neste caso relaciona- 
do à compreensão dos fatores que definem o território do APL, seguem apresentados a partir de figuras com textos explicativos e discussão teórica.

\section{Resultados e Discussões}

Dados coletados no Portal do Governo do Acre, no documento com seu histórico, indicam que o Estado foi criado em 15 de junho de 1962. Todavia, o documento ressalta que sua história tem inicio em tempos anteriores a essa data, desde o século XIX com a corrida da borracha, em que muitas pessoas ocupavam a região para trabalhar no corte da seringa.

No que diz respeito à economia, diversos setores contribuem para o desenvolvimento do estado, sendo os principais a indústria, comércio e serviços, como elencado no documento Acre em Números (2013), disponibilizado no Portal do Governo do Acre. Segundo o documento, também ganha destaque no contexto acreano, a economia dos produtos extrativos, tendo como principal o extrativismo de Castanha-da-Amazônia, que atingiu produção média de aproximadamente 14.000 toneladas na safra 2013/2014. A castanha é o principal produto exportado pelo Estado, correspondendo por cerca de 30\% das exportações (IBGE, 2013; ACRE EM NÚMEROS, 2013).
Realizou-se consulta no Portal do Ministério do Desenvolvimento, Indústria e Comércio Exterior (MDIC, 2015) com o intuito de se identificar a existência de Arranjos Produtivos Locais no Estado do Acre. Dados disponibilizados no MDIC (2015) demonstram que no Acre existem formações de APL, divididos em diversas categorias, considerando as potencialidades produtivas do Estado e suas microrregiões. Existem registros também da presença do Grupo de Trabalho Interinstitucional do Núcleo Estadual do Acre (NE-APL/ $\mathrm{AC})$, formado por representantes de órgãos e instituições públicas e privadas com foco no fortalecimento das cadeias e arranjos locais.

\subsection{Contexto da Castanha-da-Amazônia no Estado do Acre}

A castanha é um produto extrativo comum em diversas regiões da Amazônia, consistindo na base da economia de comunidades tradicionais que habitam no entorno da floresta.

Em consulta ao Plano de Gestão da Cadeia de Valor da Castanha-do-Brasil no Estado do Acre (SEAPROF, 2014), e dados da pesquisa de campo, tem-se ideia da dinâmica que envolve a atividade extrativa, desde que a castanha é coletada até chegar ao mercado, conforme apresentado na Figura 1.

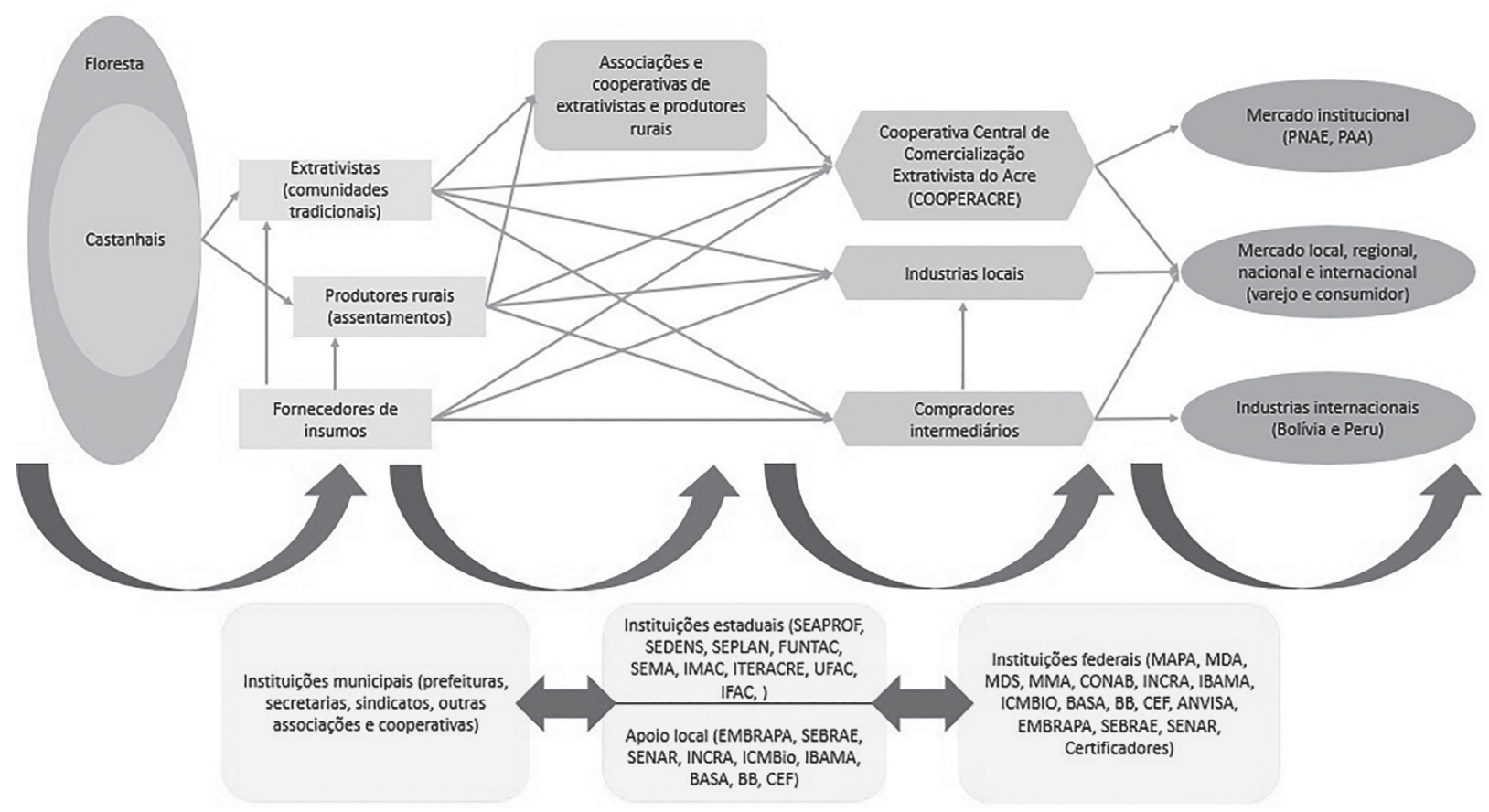

Figura 1: dinâmica da cadeia de valor da Castanha-da-Amazônia

Fonte: Adaptada de SEAPROF (2014) 
Essa dinâmica apresentada na Figura 1 contempla as etapas da cadeia da Castanha e os envolvidos, como foi elencado por Souza Filho et al. (2001), destacando que a dinâmica em que se insere a cadeia produtiva da castanha é uma importante fonte de renda para os agentes, especialmente os que vivem na Amazônia, como extrativistas, povos indígenas e agricultores, dentre outros que tiram seu sustento dessa atividade.

Inicialmente, tem-se a floresta como detentora dos recursos naturais passíveis de serem aproveitados pelo homem. Um desses recursos é o castanhal, ou área da floresta com incidência de árvores Castanheiras, que produzem frutos, a Castanha-da-Amazônia, coletado pelos extrativistas e produtores rurais, dentro dos limites da colocação, da comunidade ou da propriedade.

A castanha que passa pela associação, após a secagem vai para a Cooperativa Central para ser beneficiada nas usinas locais. As demais vão para indústrias locais, também para beneficiamento, ou para indústrias internacionais, como na Bolívia e Peru, para serem processadas. A castanha processada pela Cooperativa Central é distribuída no comércio local, por meio de supermercados e para comércio na própria cooperativa. Os supermercados pegam a castanha da Cooperativa em regime de comodato, sem quantidade definida, pois se trata de um produto perecível. Assim, conforme a demanda pelo produto, o supermercado é abastecido. Existe também o comércio do fruto em feiras, sendo em forma de produto já industrializado ou in natura.

Observações e conversas informais em empreendimentos do ramo alimentício demonstraram que estes utilizam a castanha para sorvetes, bolos, biscoitos, pizzas, tapiocas e outros mais. No entanto, uma parte deste produto é adquirida no comércio informal, nas feiras e até mesmo na rua, por ser mais barato do que a castanha comprada no supermercado. Visitas em organizações, mesmo de maneira informal e observa- ções, demonstraram que a compra também é feita, em alguns casos, direto da Cooperativa Central de Comercialização Extrativista do Acre (COOPERACRE), ou de agroindústrias locais, bem como em supermercados, feiras, nas ruas e nos sítios que possuem disponibilidade do produto.

A Castanha industrializada é comercializada em grande escala para fora do Estado, atendendo especialmente as regióes sul e sudeste. Esta informação foi concedida pelo entrevistado da indústria Casa do Seringueiro, que comercializa o produto para fora do Estado e também para outros países, especificamente para a Itália.

A Castanha beneficiada pela COOPERACRE, além do mercado consumidor chega ao mercado institucional por meio de políticas públicas como o Programa Nacional de Alimentação Escolar (PNAE) e o Programa de Aquisição de Alimentos (PAA), dos quais os subsídios acessados são geridos pela cooperativa e repassados aos extrativistas por meio das associações e cooperativas que os representam.

Os insumos utilizados pelas indústrias, como embalagens e tecnologias, são importados de outras regiões fora do Estado e até mesmo de outros países, pois, o Estado do Acre não produz estes insumos.

A partir das entrevistas realizadas e consultas em documentos, como o Plano de Gestão da Cadeia de Valor da Castanha-do-Brasil no Acre, observa-se que a produção de Castanha é uma atividade que envolve diversos atores sociais, agentes de representação e parceiros. No Acre, essa é uma das principais atividades econômicas do Estado, sendo a principal atividade extrativa da região, conforme o Informativo Acre em Números (2013), se inserindo em uma dinâmica que envolve diversas esferas econômicas, sociais, ambientais, políticas e culturais, empenhadas no alcance de objetivos e capazes de se articularem para a promoção do deenvolvimento local. 


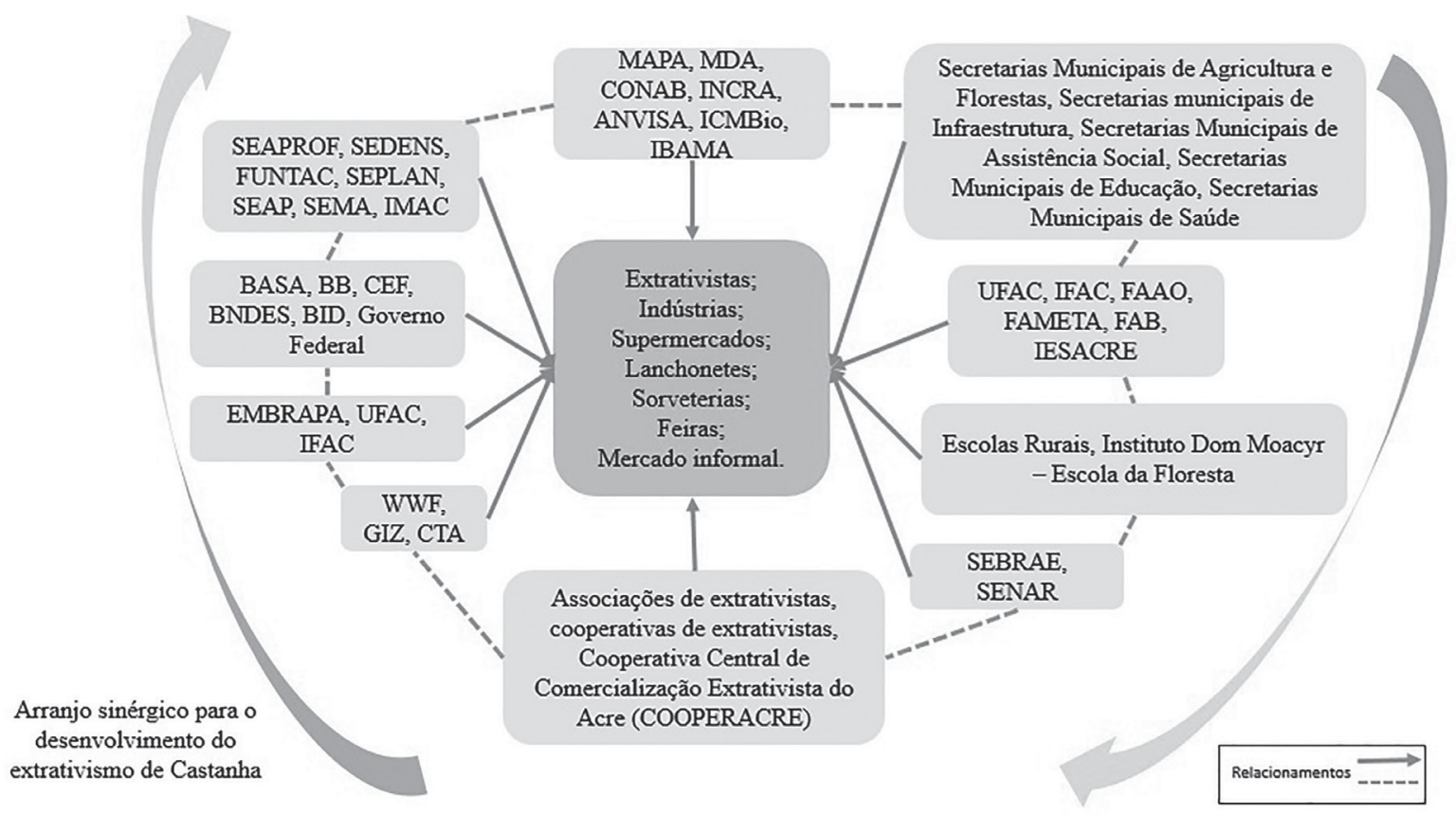

Figura 2: dinâmica do APL da Castanha-da-Amazônia no Estado do Acre Fonte: Dados da pesquisa, com base em Paes-de-Souza (2007)

Visando o desenvolvimento e o fortalecimento da atividade, diversas parcerias e articulações diretas e indiretas são instituídas com agentes locais. Os agroextrativistas são organizados e representados por instituições como associações e cooperativas, que se articula com outras instituições parceiras, direta ou indiretamente. Os contatos diretos são com os agentes locais, como os órgãos municipais, as instituições pertencentes ao espaço geográfico do arranjo como sindicatos e o comércio local, sendo indústrias, supermercados, feiras, lanchonetes, panificadoras, sorveterias e outros. No contexto Estadual encontram-se as instituições do Estado, secretarias e órgãos participantes das ações, que apoiam a atividade do arranjo com de políticas $e$ incentivos. No âmbito federal, os agentes, representados por instituições, se relacionam com demais instituições que interagem com o arranjo. Além desses, ocorrem também interações por meio de pesquisa, fomento, infraestrutura, treinamentos e capacitações, tudo com o intuito de favorecer a atividade e auxiliar nas estratégias de desenvolvimento local.

\subsection{O Território do APL}

Para se compreender a formação do território presente no APL da Castanha-da-Amazônia no Estado do Acre, tomou-se por base as ações desenvolvidas pelos agentes inseridos no arranjo, resultantes de suas relações sociais que se projetam no tempo e no espaço, conforme preconizado por Albagli (2004).

No arranjo, foram identificadas diversas formas de relações entre os agentes, pautadas em fatores como confiança, participação, inclusão, compra e venda de produtos, assistência técnica, apoio à organização coletiva, representação, dentre outros. Porém, percebe-se uma característica muito peculiar no APL, que consiste nos resultados das relações entre os agentes, sendo um contexto coletivo e com ações coordenadas, e outro contexto de ações isoladas e individuais. Diante disso, já se percebem indicativos da existência de mais de um território, pois segundo Haesbaert e Limonad (2007), o território é formado a partir das ações desenvolvidas pelos indivíduos enquanto "ser sociail", que se relaciona em busca de objetivos.

As ações coletivas foram indicadas no contexto do arranjo que é coordenado pela COOPERACRE e seus parceiros. Nesse cenário, segundo relatos dos entrevistados, os agentes são organizados, participam e são engajados nas tomadas de decisões, facilitando a comunicação $e$ interação por meio de fluxos de informações disseminadas.

Prova disso é a ampla divulgação do manual de boas práticas pela SEAPROF, adotado pela COOPE- 
RACRE, conhecido e aplicado por suas filiadas. Esses fatores proporcionam articulação entre os agentes, de maneira que se possam firmar parcerias, destacando-se neste sentido o Governo do Estado e o Governo Federal por meio de seus órgãos, possibilitando-se acesso às políticas públicas como PNAE, PAA e PROACRE - acessadas pela COOPERACRE e repassadas aos extrativistas por meio das suas associações e cooperativas -, melhoria na renda das famílias a partir de melhores preços alcançados pela castanha com valor agregado pela Cooperativa Central, desenvolvimento do capital social, sintonia com ações constantes $e$ articuladas, trocas de experiências e aprendizados coletivos, participação nas ações, fazendo com que os agentes se sintam integrantes do processo de desenvolvimento local.

Todavia, no APL também existem ações individuais, apontadas por agentes que não se sentem inseridos nas articulações e ações do arranjo.

Essa realidade surgiu a partir da pesquisa realizada na região de Sena Madureira, localidade com bom potencial produtivo, segundo os entrevistados, e concentração de importantes agentes econômicos, políticos e sociais - Associação dos Seringueiros do Cazumbá-Iracema, ICMBio e gestão da RESEX, COOPERIACO e Casa do Seringueiro -, mas com baixa organização social.

Dos agentes inseridos nesse contexto, a COOPERIACO é filiada à COOPERACRE, com um bom relacionamento. Mas, sua gestora relata que a organização não participa das tomadas de decisões do arranjo, bem como não estabelece meios de comunicação com o ambiente, não recebe informações acerca das ações e atividades, tampouco tem assistência técnica. Segundo a entrevistada, a organização desenvolve ações próprias para auxiliar os cooperados, orientando como pode e fazendo o possível para atender suas demandas, que são muitas para poucos recursos. Esse relato é corroborado pelos demais agentes da região em suas entrevistas.
Os agentes afirmam que se sentem excluídos das ações desenvolvidas, relatando que estas são centralizadas para outra região, o que os remete a lógica dos objetivos isolados que são buscados por iniciativas próprias ou com alguma articulação incipiente com parceiros locais. Essa assimetria nas ações é evidente na Associação dos Seringueiros do Cazumbá-Iracema, em que os extrativistas entrevistados conhecem pouco acerca das ações desenvolvidas e possíveis de serem realizadas para o fortalecimento da cadeia produtiva da castanha, ficando estes à margem das políticas públicas que possam fomentar a atividade. Segundo o presidente da associação, sendo corroborado pelos extrativistas entrevistados, esse é um fator que não motiva os extrativistas a se organizarem para comercializar a castanha de forma coletiva, ficando estes sujeitos a ações de compradores intermediários que pagam preços bem abaixo do operado no mercado do produto, sem compromisso e sem retorno efetivo da renda, o que gera insatisfação. Os entrevistados da COOPERIACO também afirmam que seus cooperados se sentem excluídos e por isso não se motivam a se organizarem melhor, bem como apresentam resistência para algumas ações e atividades.

Pelos relatos dos entrevistados acerca dessa realidade no APL da Castanha-da-Amazônia no Acre, entende-se que ocorrem na região as decisões são centralizadas e as ações direcionadas, de maneira que não atendam as expectativas e nem as necessidades de todos os que se inserem no mesmo contexto, gerando exclusão e desmotivação para participarem de ações conjuntas.

Pelo exposto, pode-se compreender que o APL da Castanha-da-Amazônia no Estado do Acre possui características próprias, sendo composto de um híbrido de agentes, relações e mecanismos de coordenação $e$ controle, com articulação para objetivos coletivos e também ações individuais, isoladas, de maneira que comporte dois territórios distintos, como apresentado na Figura 3. 


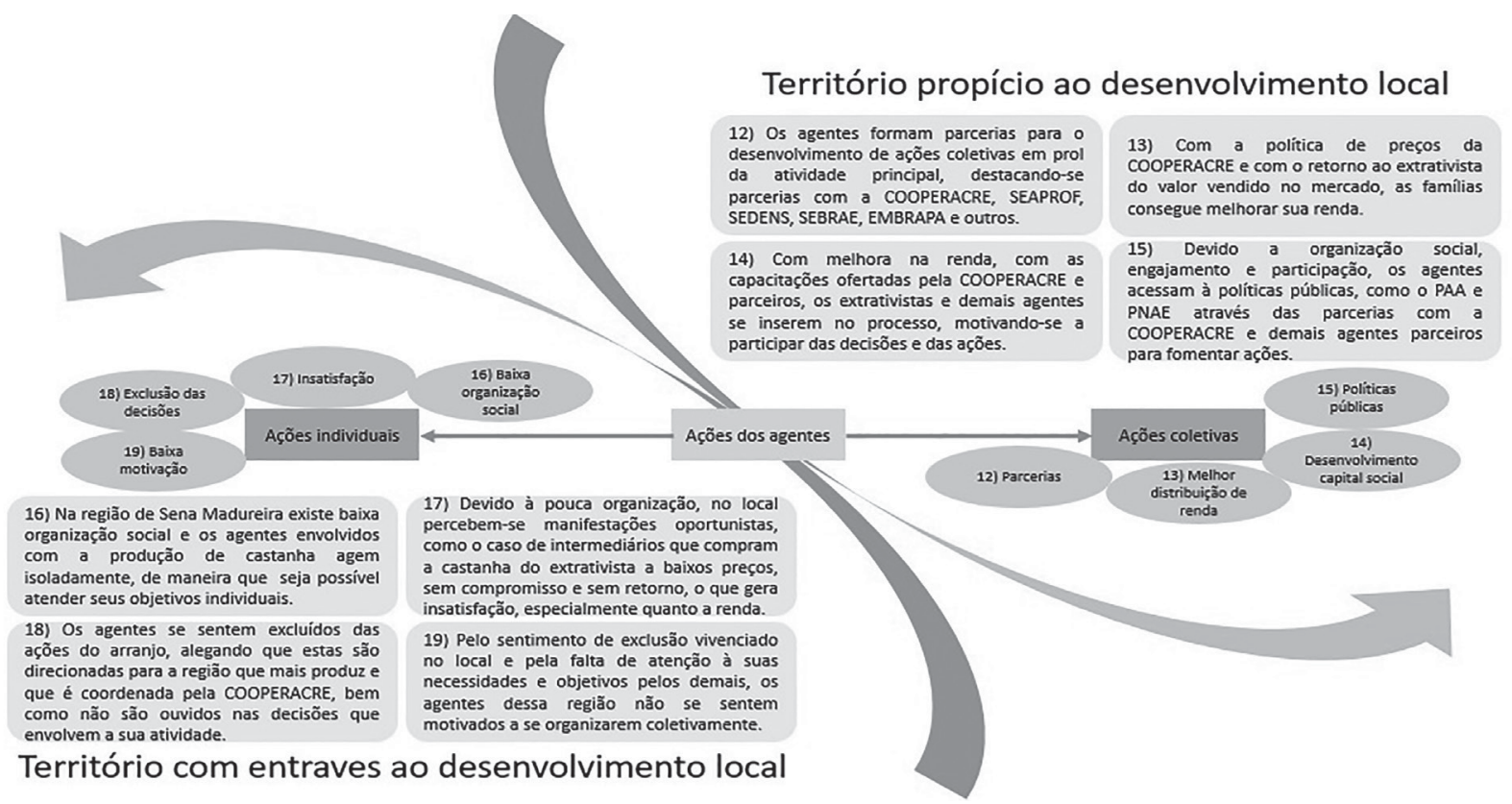

Figura 3: territórios do APL

Fonte: Dados da pesquisa

O primeiro território corresponde ao ambiente em que há um agente coordenador das atividades, no caso a COOPERACRE. Neste ambiente, os relacionamentos são articulados e geram resultados correspondentes às sinergias criadas pelos agentes e pela infraestrutura disponível. Esse cenário é caracterizado por um território de fortes relações sociais, elencado por Albagli (2004), de maneira que estas sejam prosperas e duradouras, sendo propicias ao desenvolvimento local, uma vez que possam fomentar a economia, considerando os aspectos ambientais, sociais, políticos e culturais.

O segundo território corresponde a um em que há pouca coordenação, sendo que os agentes se organizam segundo seus objetivos individuais, com pouca articulação, que por sua vez consiste em baixa sinergia e resultados pouco satisfatórios sob a ótica do desenvolvimento local. Assim, o cenário que se apresenta é caracterizado por relações fracas, isoladas e individualizadas, o que remete a um território propício a manifestações oportunistas, que são evidentes no local pela atuação de agentes que, se valendo da baixa motivação dos extrativistas, produtores e suas instituições de representação para organização social, tiram proveito comprando a castanha a preços menos significativos e enviando-a para indústrias nacionais e internacionais que lucram valores altos com o produto. Esse fator é marcante na região, uma vez que o comprador intermediário consiste, em muitos casos, na única ligação conhecida pelo extrativista para acessar o mercado e obter renda, mesmo que baixa, considerando que as informações acerca de ações possíveis para o desenvolvimento da atividade não o alcançam em seu contexto. Essa realidade coaduna com a abordagem de Little (2002), que evidencia a formação do território a partir de fenômenos e de fatores históricos, que marcam a vivência dos indivíduos e de grupos, inclusive de maneira que eles permaneçam na mesma realidade por deixarem de acreditar em possibilidades de mudanças.

Nesse sentido, compara-se o APL da Castanha-da-Amazônia no Acre com o Projeto Reca de Rondônia, segundo a pesquisa de Justen et al. (2015). Embora sejam realidades diferenciadas, especialmente pela atividade econômica principal e dimensões abrangidas, ambos apresentam estrutura de governança resultante das relações entre seus agentes, pautadas em mecanismos formais e informais. Todavia, os contextos tomam rumos diferentes quando se trata da formação dos seus territórios, pois o Projeto Reca se insere em um território de fortes relações sociais, que se projetam no espaço por longas datas e resultam em ações coletivas com objetivo nos ganhos comuns. Essa realidade promove a inclusão dos atores sociais locais nas tomadas de decisão, engajando-os com seus parceiros para ações coordenadas e organizadas, de maneira a se criar mecanismos que protejam as rela- 
ções e a atividade econômica em si contra manifestações oportunistas. Eis a questão que assola o APL da Castanha-da-Amazônia no Acre.

Uma vez que no APL existem agentes que não se inserem nas ações, abre-se uma ruptura nas relações, pois de acordo com Vilpoux e Oliveira (2010), os laços entre os agentes ficam enfraquecidos, podendo abalar as demais relações, especialmente a confiança. Os agentes, sentindo-se excluídos do arranjo que os permeia, buscam alternativas para atender seus objetivos, mesmo que tais alternativas não sejam as mais viáveis. Isso é percebido no contexto do APL da Castanha-da-Amazônia, pois os agentes que não estão engajados no arranjo, criam um segundo território, com relações sociais fracas e caracterizadas pelo oportunismo, como é o caso da presença de compradores intermediários para a castanha.

Assim, tem-se que o APL da Castanha-da-Amazônia no Estado do Acre vive uma realidade muito especifica no que diz respeito aos relacionamentos entre os agentes, pois é possível identificar dois territórios distintos, o que consiste em uma característica peculiar e, de certa forma, preocupante ao se analisar a realização de ações pautadas nas relações sociais como indutoras de articulação para o desenvolvimento local.

\section{Considerações Finais}

Diante do exposto, o objetivo geral deste trabalho, que consistiu em evidenciar os fatores que definem o território, enquanto rede de relações sociais, no contexto do APL da Castanha-da-Amazônia, a partir da compreensão dos relacionamentos desenvolvidos pelos agentes inseridos no arranjo e suas articulações para o fortalecimento da atividade produtiva em potencial, foi atendido.

Os dados apresentados e discutidos demonstraram que o APL da Castanha-da-Amazônia no Estado do Acre possui uma característica muito própria no que diz respeito às relações sociais entre os agentes, comportando dois territórios muito distintos, sendo um definido por relacionamentos consolidados e articulados, e outro por relacionamentos mais fracos devido ao pouco engajamento dos agentes locais.

Em ambos os casos, os territórios são constituídos por relações sociais projetadas no tempo e no espaço.
Todavia, os fatores que definem os territórios se apresentam de formas distintas, especialmente os fatores ligados às relações.

No primeiro território, os fatores preponderantes são as ações coletivas, inclusão dos agentes, participação nas decisões, engajamento $e$ articulação para o fortalecimento da atividade produtiva principal. Tais fatores são oriundos de relações sociais que se arrastam por longas datas, a partir das quais os agentes se mobilizaram, e continuam mobilizados, visando o desenvolvimento local. No contexto desse território, os agentes mantêm suas relações estáveis, fortalecendo as parcerias e desenvolvendo ações conjuntas, que por sua vez geram melhoria na renda dos extrativistas, melhores condições de trabalho, acesso aos mercados, capacitação e, consequentemente, desenvolvimento local.

No segundo território, a dinâmica é contrastante, pois os mesmos fatores do primeiro são visualizados de maneira diferenciada, uma vez que os agentes inseridos neste contexto alegam que se sentem excluídos do arranjo e que, mesmo se relacionando com os demais agentes e parceiros, ainda enfrentam dificuldades para a realização de ações coordenadas e organizadas para mudança da realidade local. Os agentes deste território, por não se sentirem incluídos nas ações, desmotivam-se a se organizar e se articular, buscando alternativas para geração de trabalho e renda, melhores condições de trabalho, acesso aos mercados, qualificação da produção e agregação de valor ao produto. Assim, as suas relações sociais vão enfraquecendo, o que permite que agentes oportunistas adentrem ao arranjo, com pouco compromisso social e coletivo, o que entrava o desenvolvimento local.

Diante disso, pode-se compreender que os territórios do APL em questão são definidos por fatores ligados especialmente à noção de pertencimento $e$ inclusão dos agentes no arranjo, que por sua vez determina a força ou a fraqueza das relações sociais como indutoras de ações capazes de promover o desenvolvimento local.

Como contribuição deste estudo, fica a orientação para que os relacionamentos entre os agentes do APL sejam igualitários, sem distinção, o que por sua vez pode resultar em motivação, envolvimento, participação, soma de esforços para o alcance de objetivos comuns. Assim, todo o arranjo será contemplado por uma rede de relações sociais consolidadas, capaz de 
originar em articulação e ações capazes de promover o desenvolvimento.

\section{REFERÊNCIAS}

ALBAGLI, S. Território e territorialidade. In: LAGES, Vinícius et al. (Org.). Territórios em movimento: cultura e identidade como estratégia de inserção competitiva. Rio de Janeiro: Relume Dumará, 2004. p. 23-69. Disponível em: < http://inspirebr.com.br/uploads/midiateca/ d64c55dfd943251ede2b6330035a5994.pdf>. Acesso em: 20 ago. 2014.

\section{ANDER-EGG, E. Introducción a las técnicas de}

investigación social: para trabajadores sociales. 7. ed. Buenos Aires: Humanitas, 1978.

\section{ASSOCIAÇÃO DO POVO INDÍGENA ZORÓ (APIZ).}

Boas práticas de coleta, armazenamento $e$ comercialização da castanha-do-Brasil: capacitação $e$ intercâmbio de experiências entre os povos da Amazônia mato-grossense com manejo de produtos florestais nãomadeireiros. Projeto de Conservação da Biodiversidade e Uso Sustentado das Florestas. Projeto Integrado da Castanha (PIC). Cuiabá/MT - Defanti Editora, 2008. Disponível em: <http://portal.mda.gov.br/o/1051508> . Acesso em: 16 out. 2014.

ALVARENGA, R. A. M. et al. Arranjo Produtivo Local e desenvolvimento sustentável: uma relação sinérgica no Município de Marco - Ceará. Revista de Administração Mackenzie, [S.I.], v. 14, n. 5, p. 15-43, 2013. Disponível em: <http://www.spell.org.br/documentos/ver/15005/ arranjo-produtivo-local-e-desenvolvimento-sustentavel-uma-relacao-sinergica-no-municipio-de-marco---ceara> . Acesso em: 20 jun. 2015.

BARRETO, V. M.; MONASTIRSKY, L. B. A dialética entre território e cultura na formação historicogeográfica, uma discussão teórica: breve abordagem sobre o distrito de Guaragi - Ponta Grossa (PR). Revista IDeAS, [S.l.], v. 4, n. 2, p. 307-327, 2010. Disponível em: <dialnet. unirioja.es/descarga/articulo/4059819.pdf>. Acesso em: 18 out. 2014.
BENTES-GAMA, M. M. Importância de produtos florestais não madeireiros (PFNM) para a economia regional. Circular Técnica 81. Porto Velho, RO Dezembro, 2005. Disponível em: <http://ainfo.cnptia. embrapa.br/digital/bitstream/item/24776/1/ct81produtosflorestaisnaomadeireiros.pdf $>$. Acesso em: 22 mar. 2015.

BRANDÃO, C. Territórios com Classes Sociais, Conflitos, Decisão e Poder. In: ORTEGA, A. C.; ALMEIDA F. N.

A. (Org.). Desenvolvimento territorial, segurança alimentar e economia solidária. Campinas: Editora Alínea, 2007. Disponível em: <http://www.ufpa.br/epdir/ images/docs/paper37.pdf>. Acesso em: 20 out. 2014.

CALHEIROS, D. O. Arranjo Produtivo Local: oportunidades e desafios para a implantação da cadeia produtiva da viticultura na região de Jundiaí. Revista da Micro e Pequena Empresa, Campo Limpo Paulista, v. 4, n. 1, p. 127-142, 2010.

\section{CRESWELL, J. Qualitative Inquiry and Research}

Design: Choosing among Five Approaches. 2. ed. Thousand Oaks: Sage, 2006.

EMBRAPA RONDÔNIA. Cultivo da Castanhado-Brasil em Rondônia. Sistemas de Produção, 7 , Versão Eletrônica jun./2005. Disponível em: <http:// sistemasdeproducao.cnptia.embrapa.br/FontesHTML/ Castanha/CultivodaCastanhadoBrasilRO/> . Acesso em: 21 out. 2014.

FERNANDES, B. M. Movimentos socioterritoriais e movimentos socioespaciais: contribuição teórica para uma leitura geográfica dos movimentos sociais. Revista Nera, [S.I.], ano 8, n. 6, jan.-jun. 2005. Disponível em: <http://revista.fct.unesp.br/index.php/nera/article/ viewFile/1460/1436>. Acesso em: 23 out. 2014.

FUINI, L. L. Compreendendo a governança territorial e suas possibilidades: Arranjos Produtivos Locais (APL) e circuitos turísticos. Interações, Campo Grande, v. 13, n. 1, p. 93-104, jan.-jun. 2012. Disponível em: < http://www. scielo.br/pdf/inter/v13n1/a08v13n1>. Acesso em: 18 out. 2014. 
HAESBAERT, R.; LIMONAD, E. O território em tempos de globalização. Revista Eletrônica de Ciências

Sociais Aplicadas e Outras Coisas,, [S.l.], v. 1, n. 2-4, p. 39-52, agosto, 2007. Disponível em: <http://www.uff. br/etc/UPLOADs/etc\%202007_2_4.pdf>. Acesso em: 18 out. 2014.

HOMMA, A. K. O.; MENEZES, Antônio José Elias Amorim de. Avaliação de uma Indústria Beneficiadora de Castanha-do-Pará, na Microrregião de Cametá, PA Comunicado Técnico n. 213. Belém, PA, setembro, 2008. Disponível em: <http://ainfo.cnptia.embrapa.br/ digital/bitstream/item/28767/1/ComTec213.pdf $>$. Acesso em: 15 nov. 2014.

HUMPHREY, J; SCHMITZ, H. Principles for promoting clusters \& networks of SMEs. Small Enterprises Medium Programme. Number 1, october 1995. Acesso em: 03/11/14

HURTIENNE, Thomas. Agricultura familiar e desenvolvimento rural sustentável na Amazônia. Novos Cadernos NAEA, [S.l.], v. 8, n. 1, p. 19-71, jun. 2005. Disponível em: <http://www.periodicos.ufpa.br/index.php/ ncn/article/view/47/42>. Acesso em: 8 nov. 2014.

JUSTEN, G. S. et al. Estruturas de Governança em Arranjos e Sistemas Produtivos Locais: o caso do Projeto Reca. Organizações em contexto, São Bernardo do Campo, v. 11, n. 21, jan.-jun. 2015. Disponível em: <https://www.metodista.br/revistas/revistas-metodista/ index.php/.../4684 >. Acesso em: 4 jul. 2015.

KERLINGER, F. Metodologia da pesquisa em ciências sociais. São Paulo: EPV-EDUSP, 1979.

LASTRES, Helena M. M. et al. Globalização de Inovação Localizada. Nota técnica n. 01/98. Rio de Janeiro, março de 1998.

\section{LASTRES, H. M. M.; CASSIOLATO, J. E. Glossário de} arranjos e sistemas produtivos $e$ inovativos locais: Rede de Pesquisa em Sistemas Produtivos e Inovativos Locais (REDESIST). Novembro, 2003. Disponível em: <http://www.mdic.gov.br/arquivos/dwnl_1289323549. pdf $>$. Acesso em: 15 set. 2014.
LISBOA, S. S. A importância dos conceitos da geografia para a aprendizagem de conteúdos geográficos escolares. Revista Ponto de Vista, [S.l.], v.4. 2007. Disponível em: <http:/www.coluni.ufv.br/revista/docs/volume04/ importanciaConceitosGeografia.pdf>. Acesso em: 20 nov. 2014.

LITTLE, P. E. Territórios sociais e povos tradicionais no Brasil: por uma antropologia da territorialidade. Brasília, DF: UNB, 2002. (Série Antropológica). Disponível em: <http://nute.ufsc.br/bibliotecas/upload/ paullittle.pdf $>$. Acesso em: 18 out. 2014.

\section{MACHADO, F. S. Manejo de produtos florestais não} madeireiros: um manual com sugestões para o manejo participativo em comunidades da Amazônia. Rio Branco, Acre: PESACRE; CIFOR, 2008.

MARSHALL, A. Principles of economics [1890]. 8th ed. London: Macmillan and Co. 1920. Disponível em: <http://files.libertyfund.org/files/1676/Marshall_0197_ EBk_v6.0.pdf >. Acesso em: 18 set. 2014.

PAES-DE-SOUZA, M. Arranjo produtivo local do leite na região central do Estado de Rondônia. In: CAMPOS, Indio (Org.). Plano de desenvolvimento sustentável da Amazônia Legal - Estudos - Diagnósticos de aglomerações (PDSA) 2005-2008. Belém/PA: Agência de Desenvolvimento da Amazônia (ADA), 2007.

PATIAS, T. Z. et al. Uma análise do capital social no Arranjo Produtivo Local do Leite de Santana do Livramento. Desenvolvimento em Questão, [S.l.], v. 13, n. 30, p. 175-202, 2015. Disponível em: < http:// www.spell.org.br/documentos/ver/34936/uma-analisedo-capital-social-no-arranjo-produtivo-local-do-leite-desantana-do-livramento>. Acesso em: 25 jun. 2015.

PEDROZO, E. Á. et al. Produtos Florestais Não Madeiráveis (PFNMS): as Filières do Açaí e da Castanha da Amazônia. Revista de Administração e Negócios da Amazônia, [S.l.], v. 3, n. 2, 2011. Disponível em: < http://www.periodicos.unir.br/index.php/rara/article/ view/201>. Acesso em: 8 dez. 2014.

REIS, J. dos. Uma epistemologia do território. Lisboa, PT: Instituto Superior de Economia e Gestão, da Universidade Técnica de Lisboa, 2002. Disponível em: $<$ http://www.uesc.br/cpa/artigos/uma_epistemiologia_ territorio.pdf $>$. Acesso em: 18 out. 2014. 


\section{SALES, G. O. Arranjo Produtivo Local como}

estratégia de desenvolvimento para a cadeia produtiva da Castanha-do-Brasil no Estado do Acre.

2009. 145 p. Dissertação (Mestrado) - Universidade Federal do Acre, Acre, 2009. Disponível em: < http:// www.ufac.br/portal/unidades-academicas/pos-graduacao/ mdr/documentos/dissertacoes/dissertacoes-de-2009/

GARDNIADEOLIVEIRASALES.pdf>. Acesso em: $5 \mathrm{dez}$. 2014.

SALOMÃO, R. P. A castanheira: história natural e importância socioeconômica. Museu Paraense Emílio Goeldi/MCTI. Bol. Mus. Para. Emílio Goeldi. Cienc.

Nat., Belém, v. 9, n. 2, p. 259-266, maio-ago. 2014.

Disponível em: <http:/www.museu-goeldi.br/editora/bn/ artigos/cnv9n2_2014/introducao.pdf $>$. Acesso em: 3 dez. 2014.

SANTOS, O. V. dos. Estudo das potencialidades da castanha-do-brasil: produtos e subprodutos. 2009. 214 p. Tese (Doutorado) - Faculdade de Ciências Farmacêuticas da Universidade de São Paulo (USP), São Paulo, 2009. Disponível em: <www.teses.usp.br/teses/.../Tese Orquidea_Vasconcelos_dos_Santos.pdf $>$. Acesso em: 24 jun. 2015.

SOUZA FILHO, T. A. de; PEDROZO, E. Á.; PAESDE-SOUZA, M. Produtos Florestais Não-Madeiráveis (PFNMs) da Amazônia: uma visão autóctone da cadeiarede da castanha-da-amazônia no estado de Rondônia.

Revista de Administração e Negócios da Amazônia, Amazonia, v. 3, n. 2, maio/ago. 2011. Disponível em: $<$ http://www.periodicos.unir.br/index.php/rara/article/ view/199/232 > . Acesso em: 1º dez. 2014.
SOUZA FILHO, T. A. de et al. Sustentabilidade Socioambiental e os Stakes na Cadeia Produtiva da Castanha-da-amazônia. In: XXXVIII ENCONTRO DA ANPAD. Rio de Janeiro, RJ, 13 a 17 de setembro de 2014. Anais... ANPAD, Rio de Janeiro, 2014. p. 1-13. Disponível em: <http://www.anpad.org.br/admin/ pdf/2014_EnANPAD_ESO1797.pdf $>$. Acesso em: $1^{\circ} \mathrm{dez}$. 2014.

TAHIM, E. F. Inovação e meio ambiente: o desafio dos arranjos produtivos de cultivo de camarão em cativeiro no estado do Ceará. 2008. 318 p. Tese (Doutorado_ Universidade Federal do Rio de Janeiro (UFRJ), Rio de Janeiro, 2008). Disponível em: <http://www.redesist. ie.ufrj.br/nt_count.php?projeto $=\mathrm{ts} 1 \& \operatorname{cod}=14>$. Acesso em: 15 out. 2014.

VILPOUX, O. F; OLIVEIRA, E. J. de. Instituições informais e governanças em Arranjos Produtivos Locais. R. Econ. contemp., Rio de Janeiro, v. 14, n. 1, p. 85111, jan.-abr. 2010. Disponível em: <http://www.scielo.br/ pdf/rec/v14n1/a05v14n1>. Acesso em: 12 set. 2014. 